\title{
Letter of response to: spheno-orbital meningiomas
}

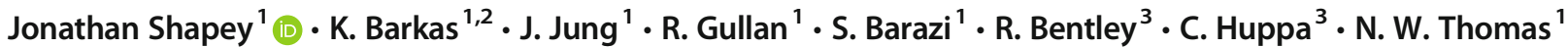

Received: 8 October 2019 / Accepted: 8 October 2019 /Published online: 9 November 2019

(C) Springer-Verlag GmbH Austria, part of Springer Nature 2019

Dear editor,

We are grateful to Professors Amirjamshidi and Abbassioun for their comments on our research and for drawing attention to their work. We were not previously aware of this study and acknowledge that we could have included it in our bibliography of related literature.

However, there are several points of difference between our study and that of Amirjamshidi et al.'s [1]. Firstly, their definition of a spheno-orbital meningioma only included those patients with "en plaque" disease involving the bone. The authors comment that in some cases soft tumour tissue extended extracranially beneath the temporalis muscle, but there is no mention of intradural involvement. In contrast, all patients in our study had an intradural tumour, often associated with bony disease. We agree with Amirjamshidi and Abbassioun that a standard pterional approach is not as effective as an orbitozygomatic craniotomy or lateral orbitotomy when trying to access the superior orbital fissure or when inferior drilling is required for tumour removal. However, performing surgery via a small lateral orbitotomy approach would not have been appropriate for our patients because of the difficulty in achieving adequate intradural tumour resection when approaching the tumour from below, and the difficulty in achieving adequate decompression of the optic nerve via this approach. The incidence of post-operative visual deficit (25\%) and enophthalmos $(5.3 \%)$ was also higher in Amirjamshidi et al.'s study which may have resulted from a more restricted approach.

In conclusion, we maintain that a standard or modified mini-orbitozygomatic craniotomy allows the optimum access to larger tumours, particularly those with intradural involvement and those with visual problems, and that good cosmetic outcomes may be achieved when combining this approach with the use of custom-made implants [2].

\section{References}

1. Amirjamshidi A, Abbasioun K, Amiri RS, Ardalan A, Hashemi SMR (2015) Lateral orbitotomy approach for removing hyperostosing en plaque sphenoid wing meningiomas. Description of surgical strategy and analysis of findings in a series of 88 patients with long-term follow up. Surg Neurol Int 6:79

2. Shapey J, Jung J, Barkas K, Gullan R, Barazi S, Bentley R, Huppa C, Thomas NW (2019) A single centre's experience of managing spheno-orbital meningiomas: lessons for recurrent tumour surgery. Acta Neurochir 161(8):1657-1667

Publisher's note Springer Nature remains neutral with regard to jurisdictional claims in published maps and institutional affiliations.

This article is part of the Topical Collection on Tumor - Meningioma

Jonathan Shapey

jshapey@doctors.org.uk

1 Department of Neurosurgery, King's College Hospital, London SE5 9RS, UK

2 Department of Neurosurgery, Hellenic Red Cross Hospital, Athens, Greece

3 Department of Oral and Maxillofacial Surgery, King's College Hospital, London, UK 